\title{
Clinical Study of the Lateral Supramalleolar Flap in the Soft Tissue Reconstruction around the Ankle Region
}

\author{
G. I. Nambi ${ }^{1} \quad$ T. K. Arudra Varanambigai ${ }^{2}$ \\ 1Plastic, Burns, Hand and Microsurgical Services, Kavin Medical \\ Center, Erode, Tamil Nadu, India \\ 2Medical Student, Government Medical College and ESI Hospital, \\ Coimbatore, Tamil Nadu, India
}

\author{
Address for correspondence G. I. Nambi, MS, MCh, FICS, Plastic, \\ Burns, Hand and Microsurgical Services, Kavin Medical Center, \\ Perundurai Road, Erode-638011, Tamil Nadu, India \\ (e-mail: nambi75@rediffmail.com).
}

Indian J Plast Surg 2020;53:83-89

\author{
Abstract \\ Keywords \\ - lateral supramalleolar \\ flap \\ - fasciocutaneous flap \\ - distal leg \\ - ankle \\ - dorsum of foot
}

Objective The purpose of this study is to present the efficiency of the lateral supramalleolar flap which is a very useful and yet underutilized in the soft tissue reconstruction of the regions extending from the distal leg, ankle, and foot.

Methods Over a period of 3 years, 20 flaps were used in the reconstruction of soft tissue defects in the region extending from the distal leg, ankle, and foot. The location of the defects, the etiology, possible alternative flaps, outcome, and the complications were studied and presented.

Results The follow-up period of the cases was from 1 month to 18 months after surgery. Seventeen flaps survived and three were lost. All the three lost flaps were those used over the tendocalcaneal region. The lost flaps were later replaced with split skin graft after the wound was debrided and was later covered with granulation tissue.

Conclusion The lateral supramalleolar flap is a very useful flap in the regional soft tissue reconstruction around the ankle except in the tendocalcaneal region.

\section{Introduction}

In the recent times, with the increased spread and use of microsurgical knowledge and expertise, the free tissue transfer has become the choice of reconstruction for soft tissue defects of the distal third of the leg and foot. Yet there is always scope for the use of pedicle flaps when there is lack of expertise for microsurgery or when there is failure of the transferred free tissue. One such flap is the lateral supramalleolar flap that is a reliable, sturdy, and very useful to cover soft tissue defects of the distal leg, ankle, and foot but still remains underutilized and under-reported in the literature. The lateral supramalleolar flap was first described by Masquelet et al in 1988 as a pedicled fasciocutaneous flap and has been in use since then. ${ }^{1}$ Later, Valenti et al in 1991 modified the flap with a skin island and fasciocutaneous pedicle. ${ }^{2}$ Lee and Chung in 2010 described a reverse adipofascial modification of the flap to enhance more distal coverage. ${ }^{3}$ Over the years, studies have been conducted regarding its vascular axis and cutaneous supply from both the peroneal and anterior tibial vessels and it has undergone modifications in terms of its design, composition, and reach. ${ }^{4-6}$ The skin component of the flap extends from the junction of the middle and upper third of the leg proximally, $5 \mathrm{~cm}$ proximal and anterior to the lateral malleolus distally, medially the shin of the tibia, and laterally the fibula. The lateral supramalleolar flap contains the superficial peroneal nerve with its vascular plexus in its substance and it derives its vascular supply from the peroneal perforators ${ }^{4,5}$ as well as from the lateral supramalleolar branch of the anterior tibial artery and can be based on both or either one of them depending on the requirement. When this flap is based on the peroneal perforator, the arterial supply is through prograde flow and when it is based on the lateral supramalleolar artery, the arterial supply is through a retrograde flow. ${ }^{6}$ With the peroneal artery being the least involved in atherosclerotic changes and diabetic vasculopathy, this flap has always has a reliable vascular supply from one of the consistent perforators of the peroneal artery that is located within $5 \mathrm{~cm}$ proximal to the lateral malleolus.
DOI https://doi.org/

$10.1055 / \mathrm{s}-0039-3402354$ ISSN 0970-0358.
(C)2019 Association of Plastic Surgeons of India
License terms

() (1) $\Theta \circledast$ 
In this article, a retrospective study of the cases in which the lateral supramalleolar flap was used as a fasciocutaneous island pedicle flap to cover soft tissue defects in the region surrounding the ankle ${ }^{6,7}$ is presented with the analysis of results.

\section{Materials and Methods}

Over the last 3 years, 20 flaps were used in the reconstruction of soft tissue defects of the distal leg, ankle, and foot
(-Table 1). All the patients were males and the etiology was trauma, post-trauma sequelae, and infection. The left side was involved in 17 cases and the right was in 3 . The defect was situated over the anterior aspect of the ankle in one case, lateral malleolus in four cases, distal medial leg in four cases, tendocalcaneal region in three cases, distal anterior leg in three cases, medial malleolus in three cases, and dorsum of foot in two cases. The hand Doppler signal for the peroneal artery perforator and the anterior lateral supramalleolar artery were marked in all the cases. Associated reconstructive

Table 1 General data of 20 patients

\begin{tabular}{|c|c|c|c|c|c|c|c|c|c|}
\hline S.no & Sex & Age & Side & Site of defect & Etiology & Result & $\begin{array}{l}\text { Repeat } \\
\text { surgery }\end{array}$ & Follow-up & Type of flow \\
\hline 1 & $M$ & 21 & $R$ & Anterior ankle & $\begin{array}{l}\text { Silencer } \\
\text { burns }\end{array}$ & $\begin{array}{l}\text { Healed } \\
\text { well }\end{array}$ & Nil & $18 \mathrm{mo}$ & Prograde \\
\hline 2 & $M$ & 75 & $R$ & Lateral malleolus & Trauma & \begin{tabular}{|l|} 
Healed \\
well
\end{tabular} & Nil & $1 \mathrm{mo}$ & Prograde \\
\hline 3 & $M$ & 44 & L & Dorsum of foot & Trauma & \begin{tabular}{|l} 
Distal \\
margin \\
epider- \\
molysis
\end{tabular} & Nil & $4 \mathrm{mo}$ & Prograde \\
\hline 4 & $M$ & 56 & $\mathrm{~L}$ & Distal medial leg & \begin{tabular}{|l|} 
Implant \\
infection
\end{tabular} & \begin{tabular}{|l|} 
Healed \\
well
\end{tabular} & Nil & $3 \mathrm{mo}$ & Prograde \\
\hline 5 & $M$ & 19 & $R$ & Tendocalcaneal & Trauma & Lost & $\begin{array}{l}\text { Debridement } \\
\text { and skin graft- } \\
\text { ing }\end{array}$ & $18 \mathrm{mo}$ & Retrograde \\
\hline 6 & $M$ & 75 & L & Tendocalcaneal & $\begin{array}{l}\text { Pressure } \\
\text { sore }\end{array}$ & Lost & $\begin{array}{l}\text { Debridement } \\
\text { and skin graft- } \\
\text { ing }\end{array}$ & $1 \mathrm{mo}$ & Retrograde \\
\hline 7 & $M$ & 37 & L & Lateral malleolus & Trauma & \begin{tabular}{|l|} 
Healed \\
well
\end{tabular} & Nil & $4 \mathrm{mo}$ & Prograde \\
\hline 8 & M & 32 & L & Distal anterior leg & Trauma & $\begin{array}{l}\text { Healed } \\
\text { well }\end{array}$ & Nil & $3 \mathrm{mo}$ & Prograde \\
\hline 9 & M & 45 & L & Medial malleolus & \begin{tabular}{|l} 
Implant \\
infection
\end{tabular} & $\begin{array}{l}\text { Healed } \\
\text { well }\end{array}$ & Nil & $3 \mathrm{mo}$ & Prograde \\
\hline 10 & $M$ & 57 & L & Distal medial leg & Trauma & $\begin{array}{l}\text { Healed } \\
\text { well }\end{array}$ & Nil & $6 \mathrm{mo}$ & Prograde \\
\hline 11 & $M$ & 25 & L & Lateral malleolus & Trauma & $\begin{array}{l}\text { Healed } \\
\text { well }\end{array}$ & Nil & $4 \mathrm{mo}$ & Prograde \\
\hline 12 & M & 27 & L & Distal anterior leg & Trauma & $\begin{array}{l}\text { Healed } \\
\text { well }\end{array}$ & Nil & $3 \mathrm{mo}$ & Prograde \\
\hline 13 & M & 44 & L & Dorsum of foot & Trauma & \begin{tabular}{|l|} 
Healed \\
well
\end{tabular} & Nil & $2 \mathrm{mo}$ & Prograde \\
\hline 14 & $M$ & 59 & L & Lateral malleolus & $\begin{array}{l}\text { Diabetic } \\
\text { infection }\end{array}$ & \begin{tabular}{|l|} 
Healed \\
well
\end{tabular} & Nil & $3 \mathrm{mo}$ & Prograde \\
\hline 15 & $M$ & 65 & L & Distal medial leg & $\begin{array}{l}\text { Diabetic } \\
\text { infection }\end{array}$ & \begin{tabular}{|l|} 
Healed \\
well
\end{tabular} & Nil & $7 \mathrm{mo}$ & Prograde \\
\hline 16 & $M$ & 43 & L & Medial malleolus & Trauma & \begin{tabular}{|l|} 
Healed \\
well
\end{tabular} & Nil & $4 \mathrm{mo}$ & Prograde \\
\hline 17 & M & 54 & L & Medial malleolus & Trauma & $\begin{array}{l}\text { Healed } \\
\text { well }\end{array}$ & Nil & $3 \mathrm{mo}$ & Prograde \\
\hline 18 & $M$ & 35 & $\mathrm{~L}$ & Distal anterior leg & Trauma & $\begin{array}{l}\text { Healed } \\
\text { well }\end{array}$ & Nil & $6 \mathrm{mo}$ & Prograde \\
\hline 19 & $M$ & 44 & L & Distal medial leg & Trauma & $\begin{array}{l}\text { Healed } \\
\text { well }\end{array}$ & Nil & $2 \mathrm{mo}$ & Prograde \\
\hline 20 & $M$ & 32 & $\mathrm{~L}$ & Tendocalcaneal & Trauma & Lost & $\begin{array}{l}\text { Debridement } \\
\text { and skin graft- } \\
\text { ing }\end{array}$ & $1 \mathrm{mo}$ & Retrograde \\
\hline
\end{tabular}


procedures were reconstruction of Achilles tendon in one case and tibialis anterior tendon repair in one case. All the flaps were raised under tourniquet control. The largest of the flap was measuring $9 \times 9 \mathrm{~cm}$ and the smallest of the flap size was measuring $5 \times 5 \mathrm{~cm}$. Seventeen flaps had prograde vascular supply and three flaps had retrograde vascular supply. The duration of the surgery from debridement of the wound, flap marking and raising, and insetting and coverage of the flap donor site with split skin graft was within 2 hours with the average time being $1 \frac{1}{2}$ hours. Plaster slab support was given in all the cases and was maintained for 2 weeks. Nonweight-bearing ambulation was started on third day in all the cases except one in which there was fracture of the middle third of the opposite tibia. The flaps were monitored daily via a window made in the dressings and the skin graft applied to the flap donor site was inspected on fifth day and thereafter weekly follow-up was done. The duration of follow-up was from 1 month to 18 months. In this study, medical comorbid conditions such as diabetes and chronic pulmonary diseases were not considered relevant as long as the hand Doppler signals were good for the pedicle perforators.

\section{Case Reports}

\section{Case 1-Lateral Ankle Defect}

A 25-year-old male patient had sustained silencer burns to the lateral aspect of the right ankle resulting in a nonhealing ulcer for 1 month. On examination, there was a full-thickness defect in the anterolateral aspect of the right ankle measuring $\sim 7 \times 5 \mathrm{~cm}$ ( - Fig. 1A). Hand Doppler signals of the peroneal artery perforator were marked followed by flap outline (-Fig. 1B). The wound was debrided and a template of the wound size was marked and the lateral supramalleolar flap was raised ( - Fig. 1C). The flap had prograde vascular supply and after it was given inset, the donor site was covered with split skin graft ( - Fig. 1D). The flap settled well and the donor site also healed well (-Figs. 1E and F). This patient was followed up for a period of 18 months and had no issues regarding cosmesis or function.

\section{Case 2-Lateral Malleolar Defect}

A 75-year-old male diabetic patient presented with a nonhealing wound over the right lateral malleolus for the past 2 months after trivial trauma ( $\boldsymbol{- F i g}$. 2A). Preoperative hand Doppler signals of the peroneal perforator were good and the defect was covered with lateral supramalleolar flap measuring $5 \times 5 \mathrm{~cm}$ and had prograde vascular supply ( - Fig. 2B, C and D). The flap settled well in to the defect and the flap donor site healed well ( - Fig. 2E). He was followed for a period of 1 month and was later lost to follow-up.

\section{Case 3-Dorsum of Foot Defect}

A 44-year-old male patient had sustained crush injury of the left foot due to fall of heavy object and sustained fracture of the second metatarsal with avulsion of the dorsal skin

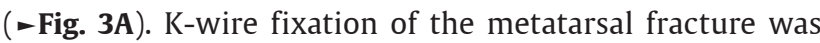
done followed by partial closure of the defect ( - Fig. 3B). Soft tissue coverage of the rest of the dorsum of foot with lateral supramalleolar flap measuring $\sim 9 \times 9 \mathrm{~cm}$ had prograde vascular supply ( - Figs. 3D and $\mathbf{E}$ ). The flap settled well into the defect except for a thin rim of epidermolysis in the distal margin that was managed conservatively and the flap donor healed well with a split skin graft ( - Fig. 3F). He was followed for a period of 4 months and had no functional issues but needed a large size foot wear due to the bulkiness of the flap.
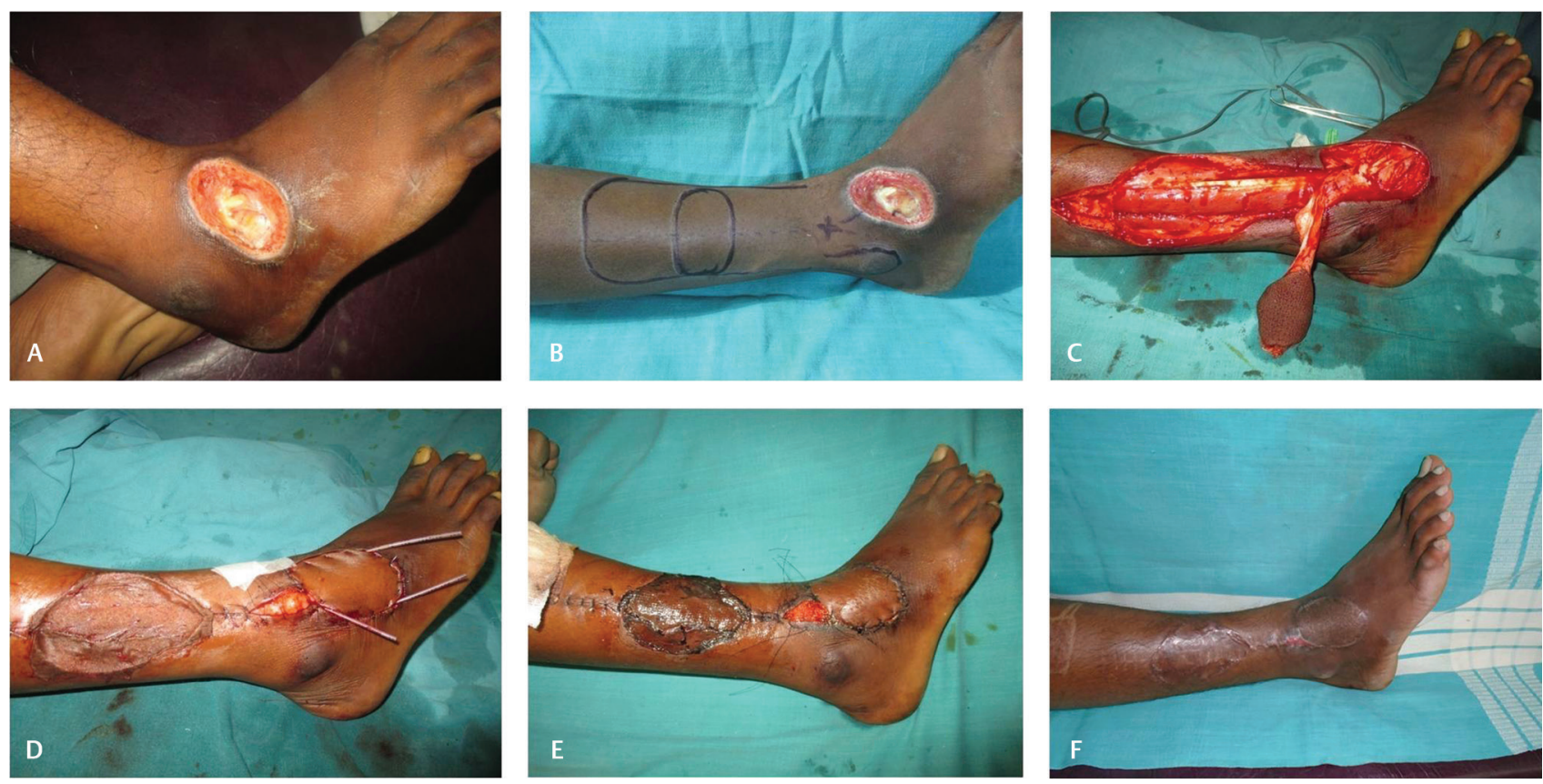

Fig. 1 (A) One-month-old soft tissue defect over the lateral aspect of the right ankle secondary to silencer burns. (B) Flap outline and marking. (C) Flap elevation. (D) Flap donor site covered with skin graft and flap inset given. (E) Early postoperative view. (F) Late postoperative view. 

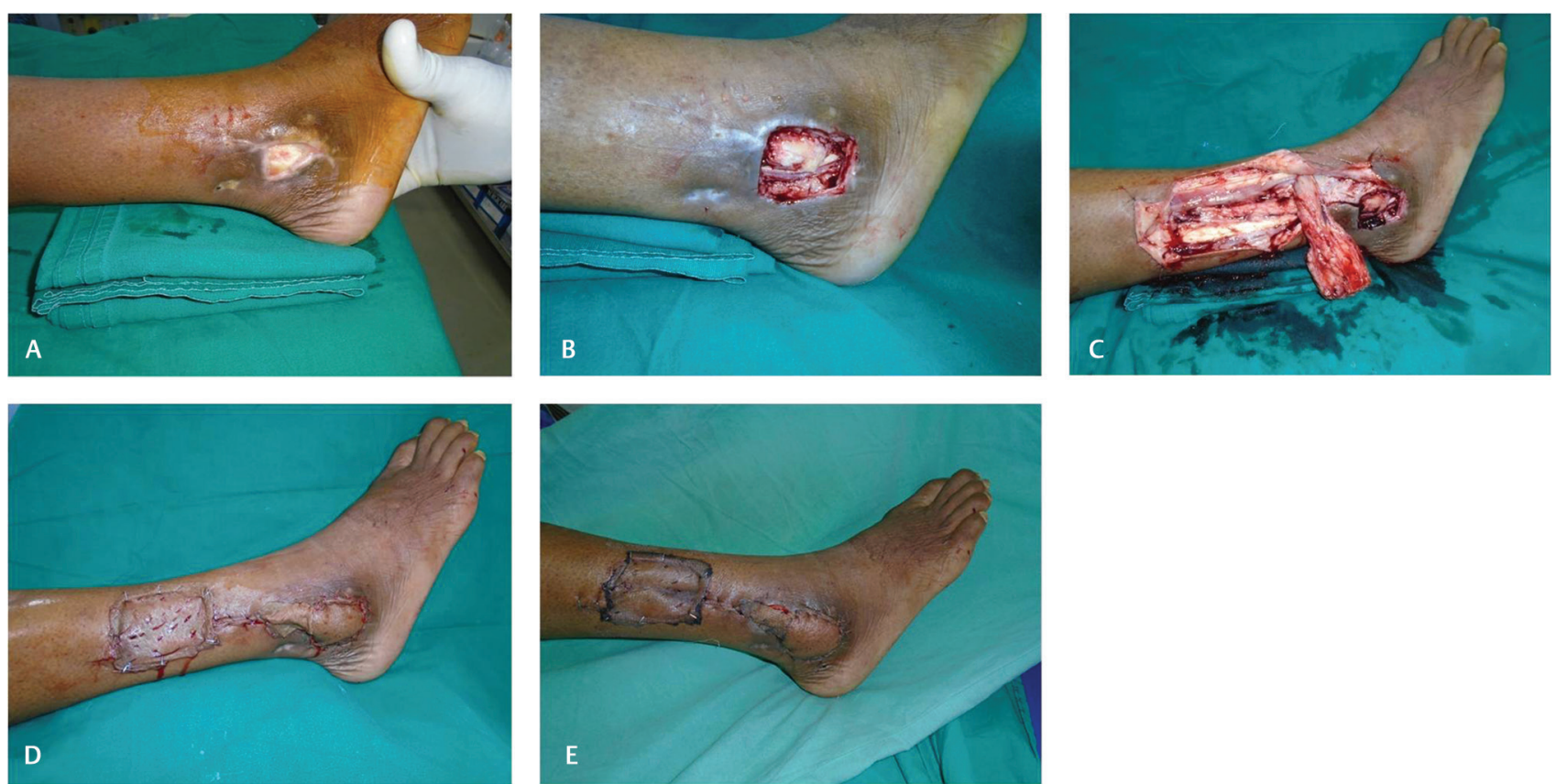

Fig. 2 (A) Diabetic wound infection. (B) Wound after debridement. (C) Flap elevation. (D) Flap inset given and donor site covered with split skin graft. (E) Late postoperative view.
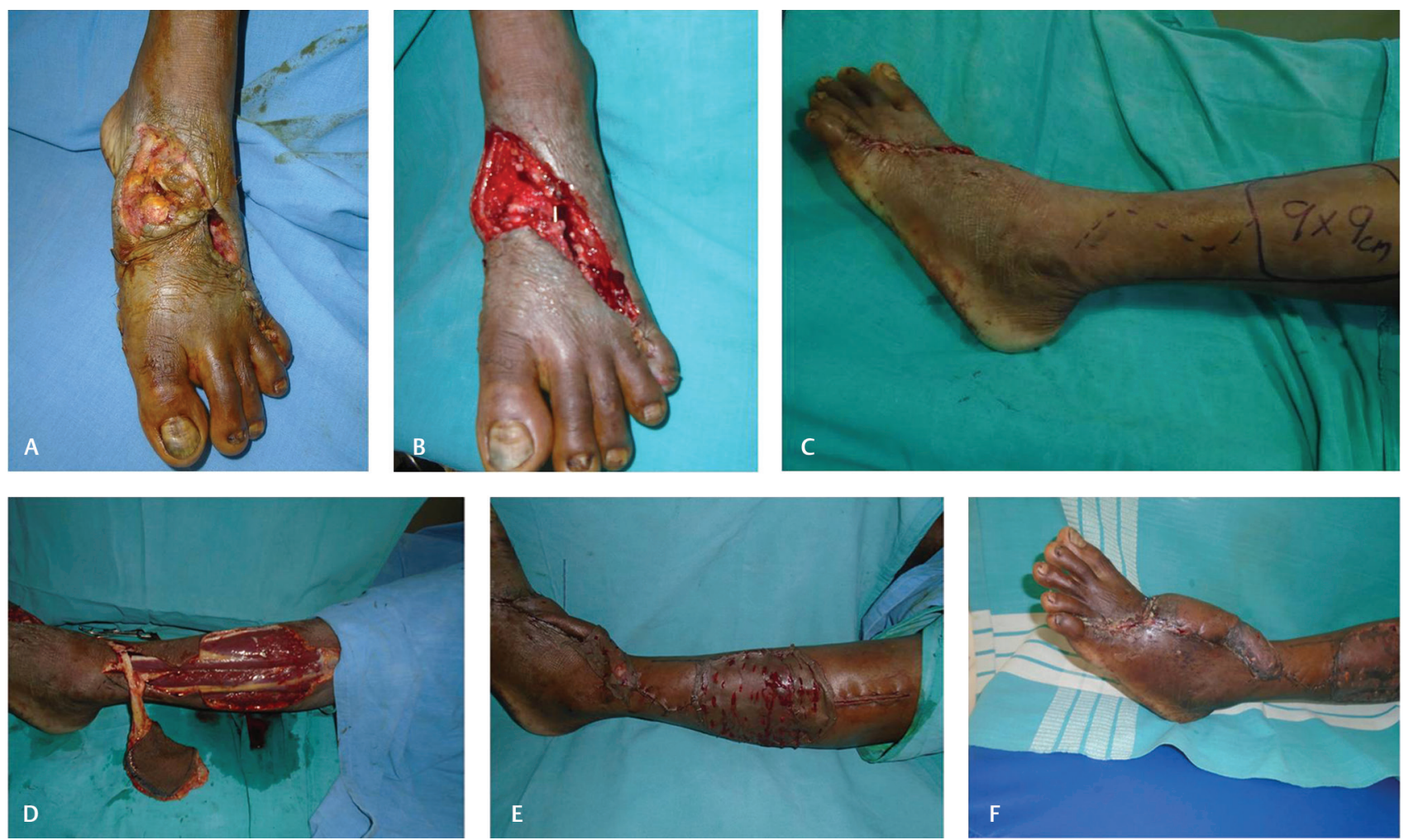

Fig. 3 (A) One-day-old post-traumatic wound over the dorsum of the left foot. (B) Wound debridement done and second metatarsal fracture stabilized with $\mathrm{K}$ wire. (C) Wound partly closed and lateral supramalleolar flap of $9 \times 9 \mathrm{~cm}$ was marked. (D) Flap elevated. (E) Flap inset to defect and flap donor site covered with skin graft. (F) Late postoperative view. 


\section{Case 4-Distal Medial Leg Defect}

A 50-year-old male patient presented with an exposed implant after fixation of distal third fracture of the left tibia with an intramedullary nail ( $\mathbf{- F i g}$. $\mathbf{4 A})$. The wound was debrided ( - Fig. 4B) and the defect was covered with a lateral supramalleolar flap measuring $9 \times 7 \mathrm{~cm}$ and had prograde vascular supply ( - Fig. 4C, D and E). The flap gave good cover to the exposed implant and the flap donor site also healed well ( - Fig. 4F). The follow-up period was 3 months and there were no issues.

\section{Case 5-Tendocalcaneal Defect}

A 21-year-old male patient presented with soft tissue defect with necrosis of the Achilles tendon in the tendocalcaneal region. The wound was debrided $(\boldsymbol{- F i g}$. $\mathbf{5 A}$ ), Achilles tendon was reconstructed ( $\boldsymbol{- \text { Fig. }} \mathbf{5 B}$ ), and the defect was covered with lateral supramalleolar flap measuring $\sim 9 \times 7 \mathrm{~cm}$ ( - Fig. 5C). Though the flap donor site healed well, the flap

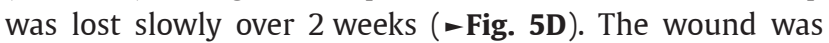
then debrided and was allowed to granulate following which split skin graft was applied ( - Fig. 5E). He was followed up for a period of 18 months and there were no functional restrictions.

\section{Results}

The follow-up period of the 20 cases was ranging from 1 to 18 months with a mean follow-up of 4.8 months. Seventeen flaps survived and three flaps were lost. All the lost flaps were used to cover soft tissue defect in the tendocalcaneal region and all the three flaps had retrograde vascular supply. The lost flaps were replaced with skin graft cover after the wound was debrided and later was covered with granulation tissue. The split skin graft over the Achilles region served well to prevent foot drop and to maintain the normal ankle movements. There were no complications at the flap donor sites covered with split skin graft.

\section{Discussion}

Microsurgical reconstruction has become the first option for reconstructing soft tissue defects of the distal lower limb in the recent years. With widespread use of microsurgical techniques, it has now become possible to give aesthetically good results with the use of super thin flaps. Yet, in this era of microsurgery, there is always scope for local pedicle flaps especially when the microsurgical free tissue transfer fails or when there is lack of microsurgical expertise as in the case of rural or remote hospitals. The most commonly used flaps in the reconstruction of distal leg, ankle and foot defects are reverse sural artery flap, lateral supramalleolar flap, peroneus brevis muscle flap, and crossed leg flaps. With crossed leg flaps being reserved as the last option owing to the practical difficulties experienced by the patient and the peroneus brevis muscle flap having limited application due to its less muscle volume and bulk, the reverse sural flap has become the most sought after flap in the reconstruction of soft tissue defects in the distal leg, ankle, and foot defects. Yet another flap in the same region, which shares certain common factors with the reverse sural flap and remains underutilized, is the lateral supramalleolar flap. ${ }^{1}$ The common factors between these two flaps are as follows: (1) They both are fasciocutaneous flap, (2) can be islanded with fascial pedicle, (3) are based on perforators from the peroneal artery, (4) have a major cutaneous nerve in their substance, (5) are distally based, (6)have adequate pedicle length, (7) have large
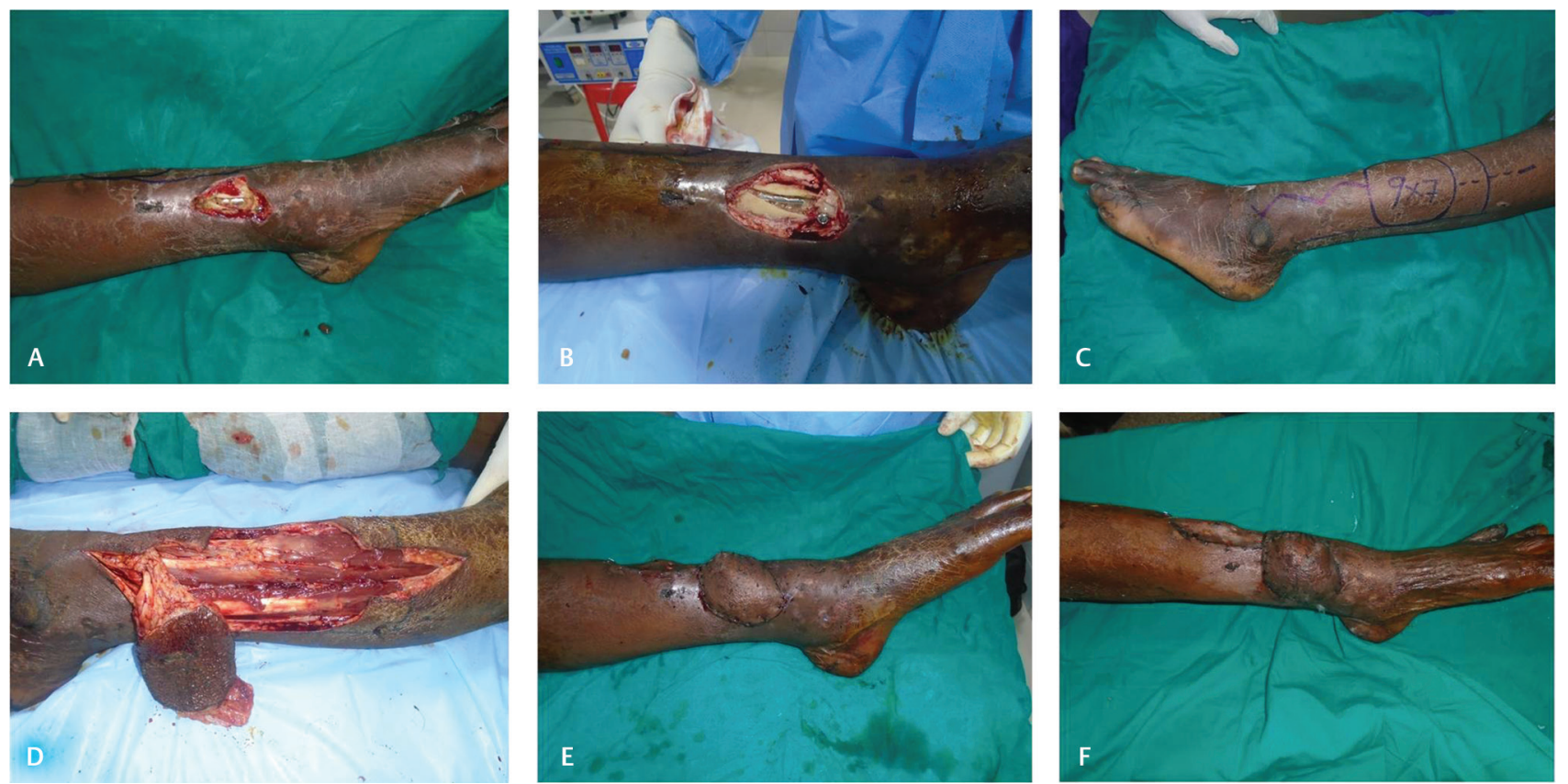

Fig. 4 (A) Soft tissue defect on the medial aspect of the left leg with exposed fracture site and implant. (B) After debridement. (C) Lateral supramalleolar flap of $9 \times 7 \mathrm{~cm}$ was marked. (D) Flap elevated. (E) Flap inset to defect and donor site covered with skin graft. (F) Late postoperative view. 

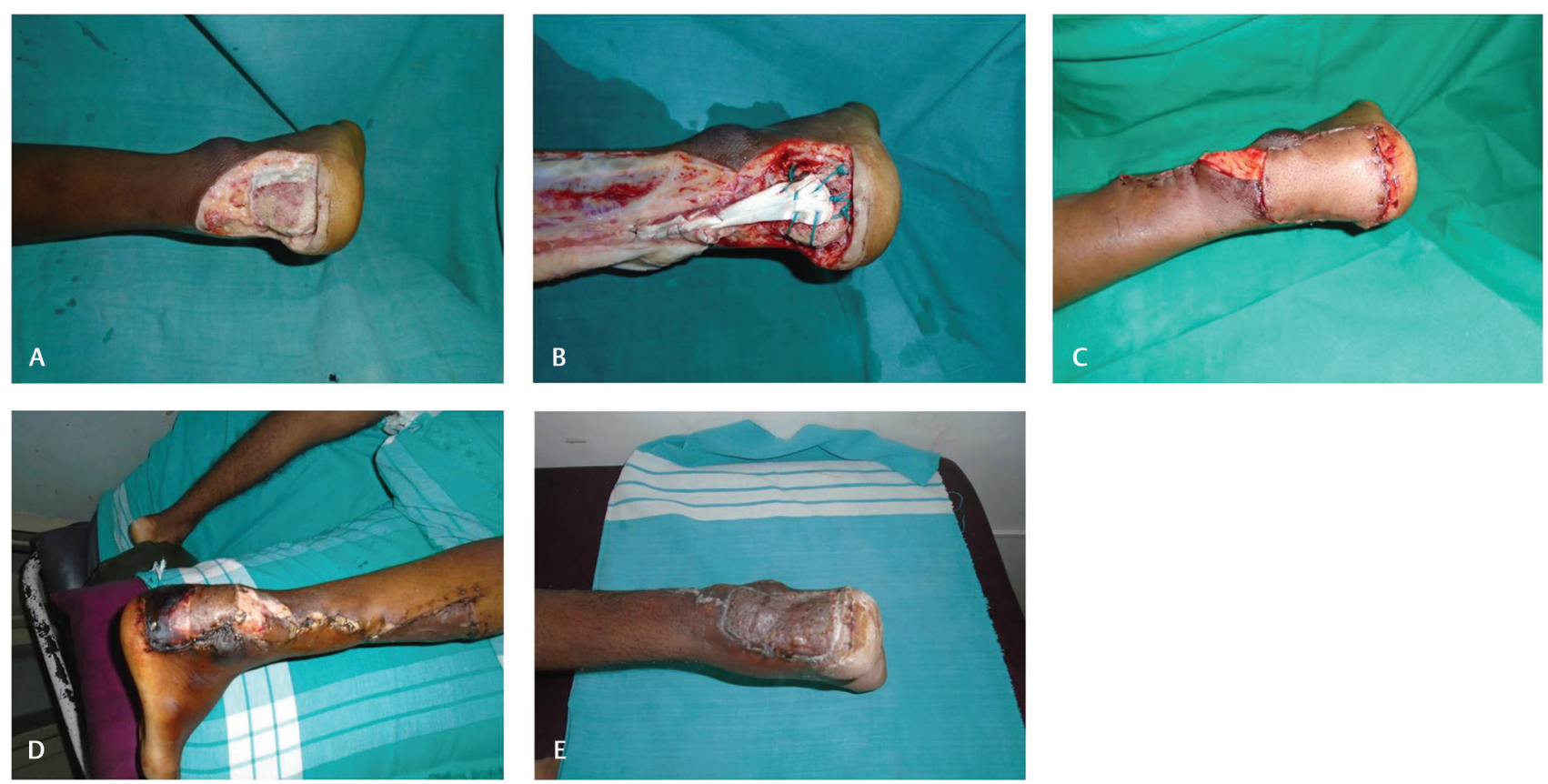

Fig. 5 (A) The defect in the tendocalcaneal region. (B) Reconstruction of the Achilles tendon with proximal mid segment flip over technique. (C) Coverage of the defect with lateral supramalleolar flap. (D) Necrosis of the flap. (E) Skin graft covering of the defect after debridement and allowing granulation tissue to develop.

skin surface area; and (8) they do not sacrifice a major artery of the corresponding length. The advantages of the lateral supramalleolar flap over the reverse sural flap are as follows: (1) The surgery can be performed with the patient in supine position; (2) It is technically less demanding; (3) This flap has a prograde vascular supply when used in proximal defects, while the disadvantages the lateral supramalleolar flap over the reverse sural flap are (1) lesser bulk, (2) limited skin area, (3) increased area of anesthesia over the dorsum of the foot, and (4) increased incidences of venous congestion ${ }^{6}$ compared with the reverse sural flap.

The lateral supramalleolar flap ${ }^{1}$ since its inception has undergone significant modifications in terms of design and clinical application owing to extensive study of the anatomy of its components ${ }^{2,3}$ and its vascular supply. ${ }^{4-6}$ The initial description of the flap being a fasciocutaneous pedicle flap, ${ }^{1}$ Valenti et $\mathrm{al}^{2}$ made the first technical modification by islanding the fasciocutaneous skin paddle and based it on a fascial pedicle so as to decrease the bulk and enable the ease of tunneling the flap. In our study, though the flaps were designed and elevated as described by Valenti et al, none of our flaps were tunneled. The skin bridge between the pedicle base and the defect was incised and after passing the flap the defect was covered with split skin graft. Lee and Chung ${ }^{3}$ described an adipofascial variant of the flap where they used only fascia along with the superficial peroneal nerve and covered the fascial flap with split skin graft at the flap recipient site. They reported $100 \%$ success rate in their series and the clinical advantage of this technique was the primary closure of the flap donor site resulting in very minimal scar and donor site morbidity. None of our flaps in this series were raised in this manner till now but future distal soft tissue reconstructions with this flap based on retrograde vascularity are being planned by this technique as described by Lee and Chung. Later modifications in the lateral supramalleolar flap were based on the extensive cadaveric studies on its vascular supply. As the flap receives its blood supply from both the peroneal and anterior tibial system through their perforators, studies were conducted on the contribution from both these systems. Akita et $\mathrm{al}^{4}$ studied about the vascular contribution of the perforating branch of the peroneal artery to the cutaneous part of the flap. They concluded that the perforating branch of the peroneal artery divides in to superficial and deep cutaneous branches after piercing the interosseous membrane. The deeper branch runs distally toward the lateral malleolus and gives perforating branches to supply the overlying skin. Based on these perforators, small and thin flaps were designed and were used to cover the defects over the lateral malleolus. The major drawback of this modification is that these flaps are technically demanding, have limited arc of rotation, and therefore cannot be used for defects other than those over the lateral malleolus. Recently, Rong et $\mathrm{al}^{5}$ studied about the vascular contribution of the anterior tibial artery to the lateral supramalleolar flap and concluded that there is a definite anastomosis between the perforating branch of the peroneal artery and the anterior lateral malleolar artery around the tibiotalar joint. They also found that there was a collateral inferolateral artery arising from the anterior tibial artery and communicating with the perforating branch of the peroneal artery at the inferior tibiofibular angle and forming an arterial arch. Cutaneous branches from this arterial arch supplied the skin around the lateral malleolus. In the absence of this arch, the cutaneous branches arose directly from the perforating branch of the peroneal artery. Unfortunately, this study was based purely on cadaveric dissections and no clinical correlation was made and therefore 
could not be compared with our study. Hamdi and Klifi ${ }^{6}$ used the lateral supramalleolar flap to reconstruct soft tissue defects around the ankle joint in children and concluded that this flap is a better alternative to the reverse sural flap when used in children. They also inferred that venous congestion is a special complication from a distally based flap in the lower limb and is common with the lateral supramalleolar flap. The possible causes of venous congestion include pedicle compression by hematoma, narrow tunnel, and valvular incompetency causing stagnation. Though we avoided tunneling of the pedicle and maintained good hemostasis throughout the procedure, the possible cause for the loss our flaps could be because of venous stagnation secondary to dependency and valvular incompetence.

In this study, the lateral supramalleolar flaps were used in the soft tissue coverage of a wide range of defects around the ankle region with good success rate. The flaps that were lost were used to cover the soft tissue defects over the tendocalcaneal region. In one case, it could be attributed to residual infection and in the remaining two, exact reason for the flap loss could not be attributed to any relevant factors. The possible reasons could be the dependent position of the flap causing venous stagnation with valvular incompetency and retrograde arterial flow from the lateral supramalleolar artery that might not have had enough arterial pressure to propel the venous blood against the gravity. Presence of medical co morbidities such as diabetes mellitus did not affect our results.

\section{Conclusion}

We infer that the lateral supramalleolar flap is a reliable flap when used as a prograde vascular flap based on contributions from the perforating branch of the peroneal artery and can be used effectively in reconstructing chronic and acute soft tissue defects in the distal leg, ankle, and dorsum of foot with good efficacy.

Note

This article was presented in Wound Care Con - 2018, Mangalore as podium presentation.

\section{Sources of Support}

None.

\section{Conflict of Interest}

None.

\section{Acknowledgment}

None.

\section{References}

1 Masquelet AC, Beveridge J, Romana C, Gerber C. The lateral supramalleolar flap. Plast Reconstr Surg 1988;81(1):74-81

2 Valenti P, Masquelet AC, Romana C, Nordin JY. Technical refinement of the lateral supramalleolar flap. Br J Plast Surg 1991;44(6):459-462

3 Lee JH, Chung DW. Reverse lateral supramalleolar adipofascial flap and skin grafting for one-stage soft tissue reconstruction of foot and ankle joint. Microsurgery 2010;30(6):423-429

4 Akita S, Mitsukawa N, Rikihisa N, et al. Descending branch of the perforating branch of the peroneal artery perforator-based island flap for reconstruction of the lateral malleolus with minimal invasion. Plast Reconstr Surg 2013;132(2):461-469

5 Rong K, Chen C, Hao LW, Xu XY, Wang ZT. Redefining the vascular classifications of the lateral supramalleolar flap. Ann Plast Surg 2016;77(3):341-344

6 Hamdi MF, Khlifi A. Lateral supramalleolar flap for coverage of ankle and foot defects in children. J Foot Ankle Surg 2012;51(1):106-109

7 Quirino AC, Viegas KC. Fasciocutaneous flaps for covering foot and ankle injuries. Rev Bras Ortop 2014;49(2):183-188 